\title{
Dynamics of bone turnover in children with GH deficiency treated with GH until final height
}

Giampiero Igli Baroncelli, Silvano Bertelloni, Cinzia Ceccarelli, Domenico Cupelli ${ }^{1}$ and Giuseppe Saggese

Endocrine Unit, Division of Pediatrics, Department of Reproductive Medicine and Pediatrics and ${ }^{1}$ Division of Orthopedics and Traumatology, Department of Endocrinology and Metabolism, Orthopedics and Traumatology, and Industrial Medicine, University of Pisa, Pisa, Italy

(Correspondence should be addressed to G I Baroncelli, Endocrine Unit, Division of Pediatrics, Department of Reproductive Medicine and Pediatrics, University of Pisa, Via Roma 67, I-56125 Pisa, Italy; Fax: +39-050-550595)

\begin{abstract}
Objective: To examine the dynamics of bone turnover in children with growth hormone deficiency (GHD) during long-term treatment.

Design: We longitudinally measured growth velocity and serum concentrations of osteocalcin (OC), carboxyterminal propeptide of type I procollagen (PICP), and cross-linked carboxyterminal telopeptide of type I collagen (ICTP) in 24 patients with GHD during long-term GH treatment until final height (age: $7.7 \pm 0.7$ and $16.9 \pm 0.5$ years at baseline and at final height respectively).

Results: At baseline, OC, PICP, and ICTP levels were significantly $(P<0.0001)$ reduced in comparison with prepubertal bone age-matched controls $(10.2 \pm 2.3 \mu \mathrm{g} / \mathrm{l}$ and $22.5 \pm 7.6 \mu \mathrm{g} / \mathrm{l} ; 187.8 \pm 26.2 \mu \mathrm{g} / \mathrm{l}$ and $328.4 \pm 74.3 \mu \mathrm{g} / \mathrm{l} ; 7.7 \pm 2.0 \mu \mathrm{g} / \mathrm{l}$ and $14.2 \pm 1.3 \mu \mathrm{g} / \mathrm{l}$ respectively). During the first year of treatment mean levels of the bone markers increased significantly $(P<0.0001)$ with a peak at 12 months. After the first year of treatment, OC and PICP levels progressively declined, whereas ICTP levels remained stable until the final height; in any case, bone marker levels remained significantly higher $(P<0.03-P<0.0001)$ than baseline. The change in bone marker levels at 6 and 12 months of treatment with respect to the baseline values was not related to growth rate during long-term treatment or final height.

Conclusions: The results show that children with GHD have reduced bone turnover at baseline, and that long-term GH treatment is associated with a stimulation of bone turnover. OC, PICP, and ICTP do not predict growth rate during long-term treatment or final height in children with GHD.
\end{abstract}

European Journal of Endocrinology 142 549-556

\section{Introduction}

It has been proposed that biochemical markers of bone turnover provide information about the dynamics of bone turnover and growth-related changes $(1,2)$. Osteocalcin (OC), a major non-collagenous protein of the bone matrix specifically secreted by osteoblasts, is considered a valid marker to examine bone formation and seems to be involved in the regulation of matrix mineralization $(1,3)$. Type I collagen, the most abundant body collagen, is a major product of osteoblasts, accounting for more than $90 \%$ of the organic bone matrix $(2,3)$. Type I collagen is also the major extracellular matrix protein of soft tissue, where it always occurs together with other collagens. Type I collagen is derived from specific precursor molecules called procollagen which is synthesized intracellularly. During synthesis, large and soluble propeptide domains are released into the circulation from the precursor molecules in a stoichiometric ratio of 1:1 (4). Serum carboxyterminal propeptide of type I procollagen (PICP) levels are generally related to the rate of bone formation $(4,5)$. Cross-linked carboxyterminal telopeptide of type I collagen (ICTP) is liberated into the serum during the degradation of mature cross-linking in type I collagen, but it is not degraded further in the bloodstream. The production rate of ICTP reflects the rate of type I collagen breakdown during bone resorption $(6,7)$. During childhood, serum levels of OC, PICP, and ICTP are much higher than in adulthood, reflecting the somatic growth rate $(1,2,8-12)$.

Some studies have shown that in children with growth hormone deficiency (GHD) the rise in serum concentrations of OC, PICP, or ICTP during the first weeks or months of growth hormone $(\mathrm{GH})$ treatment may predict growth rate at 6 or 12 months of therapy $(10,13-18)$. However, the potential value of these bone markers in predicting growth rate after the first year of treatment or final height is unknown.

In this study, we investigated the dynamics of 
bone turnover, by measuring serum concentrations of OC, PICP, and ICTP, in children with GHD longitudinally during long-term $\mathrm{GH}$ treatment until the attainment of final height. Furthermore, we assessed whether the change in serum concentrations of OC, PICP, and ICTP during the first year of $\mathrm{GH}$ treatment was related to growth rate during long-term treatment or final height.

\section{Subjects and methods}

\section{Patients}

Twenty-four Caucasian adolescents (14 males and 10 females) aged 16.0-18.0 years with isolated GHD were recruited from our Endocrine Unit at the Department of Pediatrics of our university. At the start of treatment, all patients were prepubertal (chronological age $7.7 \pm 0.7$ years, bone age $5.5 \pm 0.8$ years) and fulfilled the clinical and diagnostic criteria for GHD: $\mathrm{GH}$ peaks less than $10 \mu \mathrm{g} / \mathrm{l}$ after two provocative pharmacologic stimuli (levodopa and insulin tolerance test) and reduced spontaneous GH secretion for $24 \mathrm{~h}$ (mean GH concentrations $<3 \mu \mathrm{g} / \mathrm{l}$ ) (19). All patients had received recombinant human $\mathrm{GH}$ treatment $(0.6 \mathrm{IU} / \mathrm{kg}$ week during prepuberty and $0.9 \mathrm{IU} / \mathrm{kg}$ week during puberty, s.c. at bedtime six times a week, until the final height). The duration of the treatment ranged from 8.1 to 10.4 years with a mean of $9.2 \pm 0.7$ years. At the time of the study, all patients had attained their final height. Clinical data of the patients are reported in Table 1 . No side-effects of the treatment were observed. Compliance with the treatment was good in all patients. All patients had normal weight and length at birth, had normal renal and liver function, and did not take drugs known to affect bone or mineral metabolism. There was no history of any other chronic illness or bone disease. Karyotype, examined in all girls, was 46,XX. Seven patients (four boys and three girls) had taken part in a previous study investigating the effect of GH treatment on biochemical markers of bone turnover and bone mineral density for a period of 1 year (16).

\section{Controls}

Seventy-eight Caucasian prepubertal children (37 males and 41 females) aged 3.5-7.5 years (mean 5.7 \pm 0.7 years) and 63 adolescents (33 males, aged 16.5-18.0 years, mean $17.5 \pm 0.5$ years, Ph5G5; and 30 females, aged 15.9-17.1 years, mean $16.3 \pm 0.4$ years, Ph5B5) were enrolled as bone age-matched controls. All controls were healthy with no known medical illness, and did not receive drugs known to affect bone or mineral metabolism.

Table 1 Clinical data at baseline and at final height in children with GHD treated with GH.

\begin{tabular}{|c|c|c|c|c|c|c|c|c|}
\hline \multirow[b]{2}{*}{ Case/sex } & \multicolumn{4}{|c|}{ Baseline } & \multicolumn{4}{|c|}{ Final height } \\
\hline & $\begin{array}{c}\mathrm{CA} \\
\text { (years) }\end{array}$ & $\begin{array}{c}\text { BA } \\
\text { (years) }\end{array}$ & $\begin{array}{l}\text { Height } \\
\text { (cm) }\end{array}$ & $\begin{array}{l}\text { Height } \\
\text { (Z score) }\end{array}$ & $\begin{array}{c}\mathrm{CA} \\
\text { (years) }\end{array}$ & $\begin{array}{l}\text { Height } \\
\text { (cm) }\end{array}$ & $\begin{array}{l}\text { Height } \\
\text { (Z score) }\end{array}$ & $\begin{array}{c}\mathrm{GH} \text { therapy } \\
\text { (years) }\end{array}$ \\
\hline $1 / F$ & 6.3 & 4.2 & 98.0 & -3.2 & 16.2 & 157.3 & -0.8 & 9.9 \\
\hline $2 / \mathrm{M}$ & 6.8 & 4.6 & 103.5 & -2.9 & 16.8 & 168.2 & -1.0 & 10.0 \\
\hline $3 / F$ & 6.9 & 3.8 & 99.7 & -3.4 & 16.4 & 156.9 & -0.9 & 9.5 \\
\hline $4 / \mathrm{M}$ & 7.0 & 5.0 & 102.6 & -3.3 & 17.4 & 168.0 & -1.0 & 10.4 \\
\hline $5 / F$ & 7.1 & 5.0 & 97.2 & -4.1 & 16.3 & 156.7 & -0.9 & 9.2 \\
\hline $6 / \mathrm{M}$ & 7.2 & 4.8 & 101.7 & -3.7 & 17.0 & 165.5 & -1.4 & 9.8 \\
\hline $7 / \mathrm{M}$ & 7.3 & 4.5 & 100.5 & -3.9 & 16.9 & 166.4 & -1.3 & 9.6 \\
\hline $8 / F$ & 7.3 & 5.0 & 103.6 & -3.1 & 16.1 & 156.5 & -1.0 & 8.8 \\
\hline $9 / F$ & 7.4 & 5.4 & 102.4 & -3.3 & 16.5 & 156.0 & -1.0 & 9.1 \\
\hline $10 / \mathrm{M}$ & 7.5 & 5.5 & 103.0 & -3.6 & 17.7 & 167.2 & -1.1 & 10.2 \\
\hline $11 / \mathrm{M}$ & 7.6 & 5.0 & 104.5 & -3.4 & 17.2 & 169.0 & -0.9 & 9.6 \\
\hline $12 / F$ & 7.7 & 5.8 & 103.0 & -3.4 & 16.0 & 155.0 & -1.2 & 8.3 \\
\hline $13 / \mathrm{M}$ & 7.7 & 5.8 & 107.6 & -3.0 & 17.2 & 168.4 & -1.0 & 9.5 \\
\hline $14 / \mathrm{M}$ & 7.8 & 5.5 & 109.7 & -2.7 & 16.7 & 169.5 & -0.8 & 8.9 \\
\hline $15 / \mathrm{M}$ & 7.9 & 6.0 & 105.4 & -3.4 & 17.6 & 167.0 & -1.2 & 9.7 \\
\hline $16 / F$ & 8.0 & 6.0 & 104.2 & -3.6 & 16.8 & 156.0 & -1.0 & 8.8 \\
\hline $17 / \mathrm{M}$ & 8.1 & 6.5 & 112.0 & -2.6 & 17.5 & 169.2 & -0.8 & 9.4 \\
\hline $18 / \mathrm{M}$ & 8.2 & 6.0 & 110.0 & -3.0 & 17.0 & 166.5 & -1.2 & 8.8 \\
\hline $19 / F$ & 8.3 & 6.0 & 109.5 & -2.9 & 16.6 & 156.8 & -0.9 & 8.3 \\
\hline $20 / F$ & 8.4 & 5.5 & 104.6 & -3.8 & 16.5 & 155.6 & -1.1 & 8.1 \\
\hline $21 / \mathrm{M}$ & 8.5 & 7.0 & 108.0 & -3.6 & 18.0 & 165.0 & -1.5 & 9.5 \\
\hline $22 / F$ & 8.7 & 6.5 & 106.8 & -3.8 & 16.9 & 157.0 & -0.9 & 8.2 \\
\hline 23/M & 9.0 & 7.0 & 107.3 & -4.1 & 17.8 & 166.8 & -1.2 & 8.8 \\
\hline $24 / M$ & 9.2 & 6.5 & 107.8 & -4.2 & 17.3 & 165.9 & -1.3 & 8.1 \\
\hline Mean \pm S.D. & $7.7 \pm 0.7$ & $5.5 \pm 0.8$ & $104.7 \pm 3.8$ & $-3.4 \pm 0.4$ & $16.9 \pm 0.5$ & $162.8 \pm 5.5$ & $-1.1 \pm 0.2$ & $9.2 \pm 0.7$ \\
\hline
\end{tabular}

CA, chronological age; BA, bone age. 


\section{Study design}

In all patients, growth velocity, as well as serum concentrations of OC, PICP, and ICTP after an overnight fast were measured at baseline, between 0800 and $0900 \mathrm{~h}$, at 6 and 12 months of treatment, and subsequently every year until the attainment of final height. At baseline and at final height, serum levels of the bone markers of patients were compared with those of prepubertal and adolescent bone age-matched controls respectively. In patients, the relationships between the changes $(\Delta)$ in serum concentrations of OC, PICP, and ICTP at 6 and 12 months of treatment with respect to their baseline values and growth rate during treatment or final height were assessed. The relationship among serum levels of OC, PICP, and ICTP at baseline and during treatment, and the relationship between baseline serum levels of the bone markers and growth rate during treatment or final height were also calculated.

Ten patients (six males and four females) and 15 controls (eight males and seven females) also participated in a short-term day-to-day variability study. In patients and controls, serum levels of OC, PICP, and ICTP were measured (between 0800 and $0900 \mathrm{~h}$ ) after an overnight fast on 4 consecutive days. In patients, serum samples for measurement of the bone markers were obtained at various time-points during the study. The percent of variation of each bone marker was compared among patients, and between patients and controls.

Informed consent to perform the study was obtained from the parents of each child. The study was approved by the ethics committee for human investigation of our departments.

\section{Assessment of anthropometric findings}

Standing height was measured with a wall-mounted stadiometer by one of us. To allow a comparison between different ages and genders, growth velocity and height are expressed as Z score with respect to growth velocity S.D. and height S.D. respectively, according to the method of Tanner et al. (20) by using the formula: measured individual value-mean normal value for age and gender/S.D. of normal mean. Bone age was evaluated by using the Greulich \& Pyle method (21). The onset of puberty was assumed according to Tanner \& Whitehouse (22) when breast stage B2 was reached in girls or testicular volume reached $4 \mathrm{ml}$ in boys. Height was considered as final adult stature when height velocity during the last year was less than $2 \mathrm{~cm}$ and wrist epiphyses had fused (23).

\section{Assessment of biochemical markers}

In both patients and controls, serum samples were separated within $2 \mathrm{~h}$ of sampling and stored at $-70^{\circ} \mathrm{C}$ until assayed. Serum OC levels were measured by a twosite immunoradiometric assay (Human OC; Nichols Institute, San Juan Capistrano, CA, USA) that recognized both intact $\mathrm{OC}$ and its large N-terminal midfragment. Serum PICP and ICTP levels were detected by radioimmunoassay (Orion Diagnostics, Espoo, Finland). The method to assess ICTP used polyclonal antibodies developed in rabbits and was based on a complex peptide that contained material from three polypeptide chains, two of them being derived from the carboxyterminal telopeptide of one type I collagen molecule and the third from the triple helical region of another molecule, plus a trivalent cross-link (24). ICTP derives only from collagen degradation and is specific for type I collagen (24). For all measurements, interassay variability was less than $9 \%$ and intra-assay variability was less than $7 \%$. All blood samples were measured in duplicate.

\section{Statistical analysis}

The results are expressed as means \pm S.D. Comparison of the data between patients and controls was assessed by Student's $t$-test for unpaired samples. In patients, the paired $t$-test was employed to compare the longitudinal data during treatment. Simple and multiple regression analyses were carried out among the biochemical markers of bone turnover, and between the biochemical markers of bone turnover and growth velocity at baseline and during treatment, or final height. Multiple regression analysis, with final height $\mathrm{Z}$ score as dependent variable and growth velocity $\mathrm{Z}$ score at 6 and 12 months of treatment, age at onset of puberty, and duration of therapy as independent variables, was also calculated. All statistical analyses were carried out using the SPSS (Statistical Package of Social Sciences, Chicago, IL, USA) for Windows software program version 6.1. $P<0.05$ was considered significant.

\section{Results}

\section{Longitudinal variation of growth velocity during GH treatment and final height}

During the first year of treatment, mean growth velocity improved significantly (baseline: $2.6 \pm 0.6 \mathrm{~cm} /$ year or $-3.5 \pm 0.8 \mathrm{Z}$ score; 6 months: $9.1 \pm 1.1 \mathrm{~cm} /$ year or $4.4 \pm 1.4 \mathrm{Z}$ score, $\mathrm{P}<0.0001$ with respect to baseline; 12 months: $8.0 \pm 1.3 \mathrm{~cm} /$ year or $3.2 \pm 1.7 \mathrm{Z}$ score, $P<0.0001$ with respect to baseline). After the first year of treatment, mean growth velocity significantly declined in comparison with the mean value at 6 months of therapy, but it remained significantly higher than baseline values (Fig. 1). Mean height increased during treatment (data not shown); final height ranged from -1.5 to $-0.8 \mathrm{Z}$ score (Table 1 ).

All patients had spontaneous pubertal development during treatment; chronological age and bone age at 


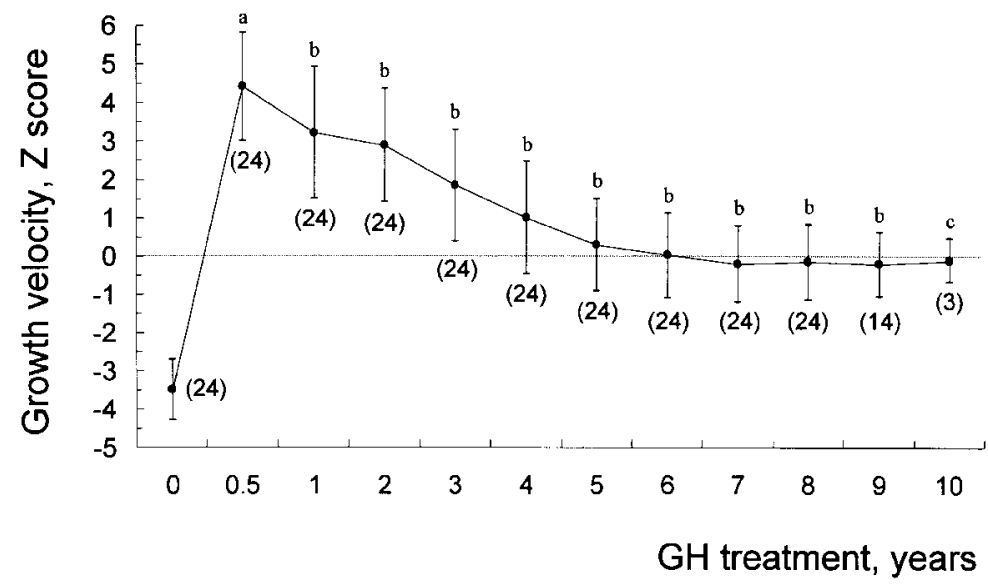

Figure 1 Longitudinal variation of growth velocity $Z$ score in children with GHD receiving recombinant human $\mathrm{GH}$ treatment. The numbers of patients are shown in parentheses. Final height was reached after 8 years $(n=10), 9$ years $(n=11)$, or 10 years $(n=3)$ of $\mathrm{GH}$ treatment. Data are expressed as means \pm S.D. ${ }^{a} P<0.0001$ in comparison with baseline values; ${ }^{b} P<0.0001$ in comparison with baseline values and $P<0.0001$ in comparison with 6 months; ${ }^{\mathrm{c}} P=$ NS in comparison with baseline values and $P=\mathrm{NS}$ in comparison with 6 months. the onset of puberty were $13.5 \pm 0.9$ years and $12.3 \pm 0.7$ years in boys, and $12.8 \pm 1.0$ years and $11.3 \pm 1.0$ years in girls respectively. Duration of the pubertal growth spurt was 3.8 years and 3.6 years in boys and girls respectively. Growth rate significantly declined during puberty (stage I: $2.3 \pm 1.5 \mathrm{Z}$ score; stage II: $1.0 \pm 1.5 \mathrm{Z}$ score, $P<0.01$ with respect to stage I; stage III: $-0.1 \pm 1.2 \mathrm{Z}$ score, $P<0.0001$ and $P<0.01$ with respect to stage I and stage II respectively; stage IV: $-0.6 \pm 1.0 \mathrm{Z}$ score, $P<0.0001$ and $P=$ not significant (NS) with respect to stage I and stage III respectively; stage V: $-0.3 \pm 1.0 \mathrm{Z}$ score, $P<0.0001$ and $P=\mathrm{NS}$ with respect to stage I and stage IV respectively). At final height, chronological age and pubertal stage were $17.3 \pm 0.4$ years and Ph5G5 in boys, and 16.4 \pm 0.3 years and Ph5B5 in girls respectively. No patient showed signs of puberty within the first year of treatment.

\section{Longitudinal variation of bone markers during GH treatment}

At baseline, mean OC, PICP, and ICTP levels were significantly reduced in patients in comparison with prepubertal controls (Table 2).

The longitudinal variation of bone markers during
$\mathrm{GH}$ treatment until the attainment of final height is reported in Fig. 2. Mean OC, PICP, and ICTP levels increased significantly at 6 months $(\Delta 16.3 \mu \mathrm{g} / \mathrm{l}, \Delta$ $205.5 \mu \mathrm{g} / \mathrm{l}$, and $\Delta 8.5 \mu \mathrm{g} / \mathrm{l}$ respectively) and peaked at 12 months of treatment $(\Delta 28.8 \mu \mathrm{g} / \mathrm{l}, \Delta 280.2 \mu \mathrm{g} / \mathrm{l}$, and $\Delta 11.8 \mu \mathrm{g} / \mathrm{l}$ respectively) with respect to baseline values. After the first year of treatment, mean OC and PICP levels progressively declined, whereas mean ICTP levels remained stable up to final height. In any case, during treatment, mean OC, PICP, and ICTP levels remained significantly higher than the baseline values.

At final height, mean OC, PICP, and ICTP levels were significantly higher than baseline values; however, mean OC and PICP levels of patients were significantly lower than those of adolescent controls, whereas mean ICTP levels were not (Table 2).

Bone marker levels did not change $(P=N S)$ during the pubertal stages (data not shown).

Day-to-day mean percent of variation of the bone markers did not differ $(P=\mathrm{NS})$ between patients and controls (OC: $15.2 \%$ and $15.8 \%$; PICP: $16.5 \%$ and 17.0\%; ICTP: $14.3 \%$ and $14.1 \%$ respectively). A similar day-to-day mean per cent of variation of the bone markers was also observed among patients (data not shown).

Table 2 Serum bone marker levels in children with GHD and in bone age-matched controls at baseline and at final height. Data are expressed as means \pm S.D..

\begin{tabular}{lccccc}
\hline & \multicolumn{2}{c}{ Baseline } & & \multicolumn{2}{c}{ Final height } \\
\cline { 2 - 3 } \cline { 5 - 6 } Bone markers & Patients & Prepubertal controls & & Patients & Adolescent controls \\
\hline OC $(\mu \mathrm{g} / \mathrm{l})$ & $10.2 \pm 2.3^{\mathrm{a}}$ & $22.5 \pm 7.6$ & & $21.8 \pm 3.4^{\mathrm{b}}$ & $39.0 \pm 15.1$ \\
PICP $(\mu \mathrm{g} / \mathrm{l})$ & $187.8 \pm 26.2^{\mathrm{a}}$ & $328.4 \pm 74.3$ & & $302.7 \pm 50.5^{\mathrm{b}}$ & $436.2 \pm 110.1$ \\
ICTP $(\mu \mathrm{g} / \mathrm{l})$ & $7.7 \pm 2.0^{\mathrm{a}}$ & $14.2 \pm 1.3$ & & $19.9 \pm 4.1^{\mathrm{c}}$ & $20.1 \pm 4.3$ \\
\hline
\end{tabular}

${ }^{\text {a }} P<0.0001$ in comparison with prepubertal controls.

${ }^{b} P<0.0001$ in comparison with baseline values and adolescent controls.

${ }^{\mathrm{c}} P<0.0001$ in comparison with baseline values and $P=\mathrm{NS}$ in comparison with adolescent controls. 


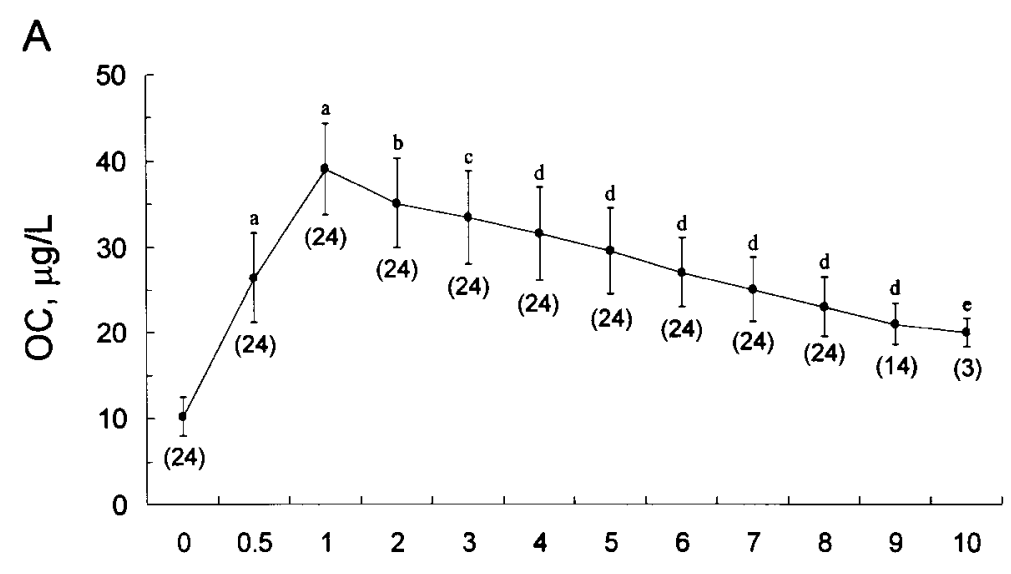

$\mathrm{GH}$ treatment, years
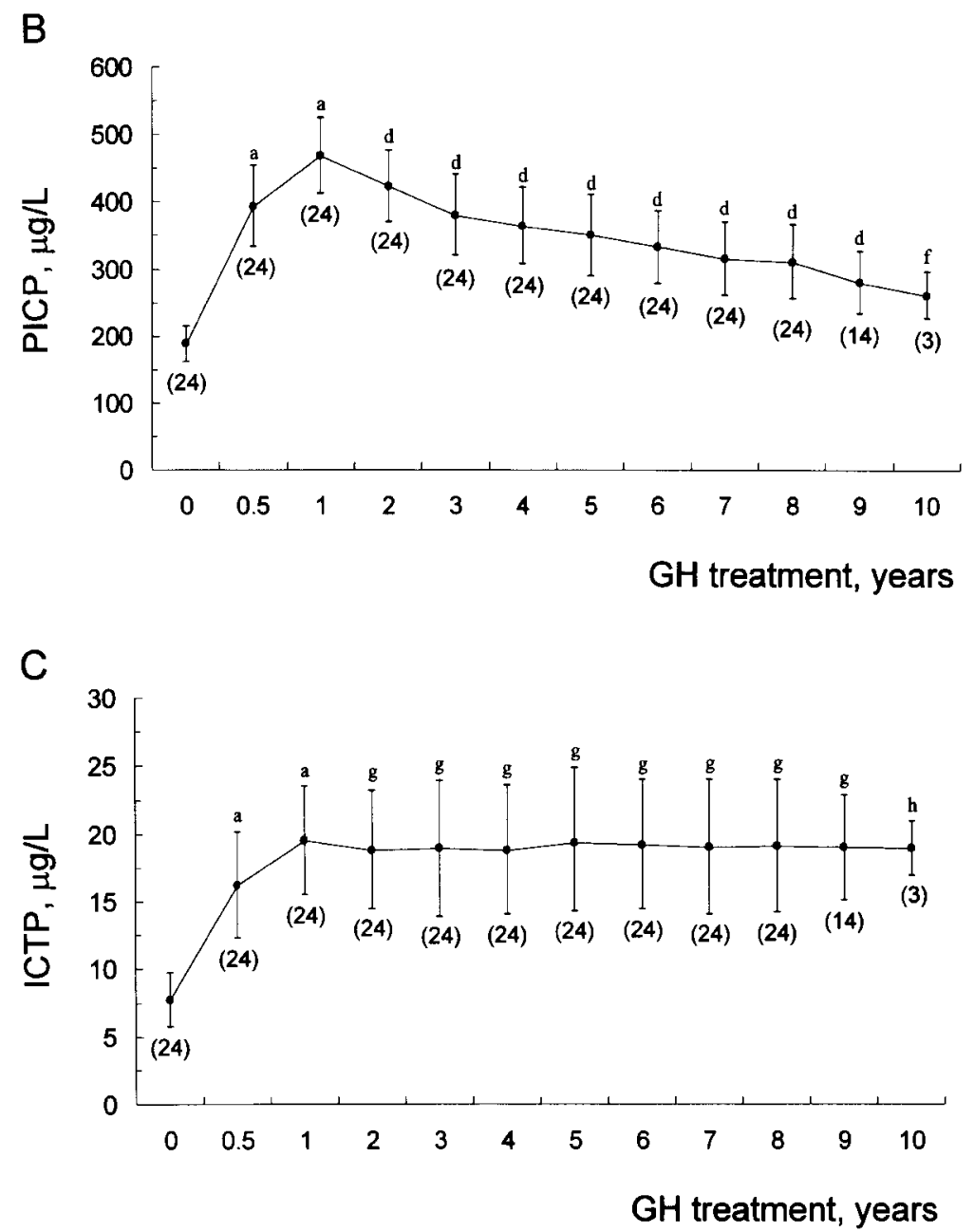

Figure 2 Longitudinal variation in mean serum concentrations of (A) OC, (B) PICP, and (C) ICTP in children with $\mathrm{GHD}$ receiving recombinant human $\mathrm{GH}$ treatment. The numbers of patients are shown in parentheses. Final height was reached after 8 years $(n=10), 9$ years $(n=11)$, or 10 years $(n=3)$ of $\mathrm{GH}$ treatment. Data are expressed as means \pm S.D. ${ }^{\text {a }} P<0.0001$ in comparison with baseline values; ${ }^{b} P<0.0001$ in comparison with baseline values and $P<0.01$ in comparison with 1 year; ${ }^{\mathrm{c}} P<0.0001$ in comparison with baseline values and $P<0.001$ in comparison with 1 year; ${ }^{d} P<0.0001$ in comparison with baseline values and $P<0.0001$ in comparison with 1 year; ${ }^{\mathrm{e}} P<0.03$ in comparison with baseline values and $P<0.03$ in comparison with 1 year; ${ }^{\mathrm{f}} P=\mathrm{NS}$ in comparison with baseline values and $P<0.01$ in comparison with 1 year; ${ }^{\mathrm{g}} P<0.0001$ in comparison with baseline values and $P=\mathrm{NS}$ in comparison with 1 year; ${ }^{\mathrm{h}} P=\mathrm{NS}$ in comparison with baseline values and $P=\mathrm{NS}$ in comparison with 1 year.

\section{Correlation between bone markers and growth velocity or final height}

At baseline, there was no correlation of serum levels of OC, PICP, and ICTP with chronological age $(r=0.13-$
$0.16, P=\mathrm{NS})$, growth velocity $\mathrm{Z}$ score $(r=0.15-0.19$, $P=\mathrm{NS})$, and height $\mathrm{Z}$ score $(r=0.07-0.24, P=\mathrm{NS})$. There was no correlation of baseline growth velocity $\mathrm{Z}$ score or baseline serum levels of OC, PICP, and ICTP with growth velocity $\mathrm{Z}$ score during treatment 
$(r=0.02-0.29, \quad P=\mathrm{NS})$ or final height $\mathrm{Z}$ score $(r=0.17-0.33, P=\mathrm{NS})$. The changes in OC, PICP, and ICTP levels at 6 and 12 months of treatment were not related to growth velocity $\mathrm{Z}$ score at baseline $(r=0.10-0.22, \quad P=\mathrm{NS})$ and during treatment $(r=0.02-0.34, P=\mathrm{NS})$, or final height $(r=0.13-$ $0.36, P=\mathrm{NS})$.

Baseline serum levels of OC, PICP, and ICTP were not related among them $(r=0.03-0.11, P=\mathrm{NS})$ or to their changes during treatment $(r=0.05-0.14, P=\mathrm{NS})$. OC and PICP concentrations correlated positively at 6 and 12 months $(r=0.36, P<0.05$ and $r=0.35, P<0.05$ respectively). There were no significant correlations between the bone formative markers OC and PICP and the bone resorptive marker ICTP during the treatment $(r=0.09-0.19, P=\mathrm{NS})$.

None of the independent variables of final height $\mathrm{Z}$ score reached significance (growth velocity $\mathrm{Z}$ score at 6 or 12 months of treatment: $r=0.30$ and $r=0.28$, $P=$ NS respectively; age at pubertal onset: $r=0.17$, $P=\mathrm{NS}$; duration of therapy: $r=0.03, P=\mathrm{NS}$ ).

\section{Discussion}

Our results demonstrate that children with GHD have reduced bone turnover and that $\mathrm{GH}$ treatment, in addition to promoting linear growth, stimulates osteoblasts and activates bone modeling and remodeling. We also show that the increment in OC, PICP, and ICTP during the first year of treatment does not predict growth rate during long-term $\mathrm{GH}$ treatment or final height.

At baseline, mean OC, PICP, and ICTP levels were significantly decreased in comparison with prepubertal controls as previously reported by us (16) and others $(10,13,14,25,26)$, indicating that bone turnover is reduced in children with GHD. The decreased PICP and OC levels probably reflected a reduced preosteoblastic collagen production and mineralization of bone matrix respectively; whereas the decreased ICTP levels expressed a reduced degradation of bone matrix (27). Reduced bone turnover is probably a main cause of decreasing bone mineral density in children with GHD $(16,28,29)$. In any case, the diminished somatic growth likely contributed to reducing the levels of the bone markers. In this context, we have demonstrated that 24-h PICP but not 24-h OC concentrations were growth velocity-dependent and $\mathrm{GH}$-dependent in children with GHD (30).

During the first year of treatment, mean levels of the bone markers significantly increased with a peak at 12 months, probably reflecting the number and the activity of the recruited osteoblasts (OC and PICP) and an increased action of osteoclasts on bone matrix or change in the activation frequency of new remodeling units (ICTP) (31). Histomorphometric analyses in men with GHD of childhood onset showed that GH doubled the activation frequency (i.e. the number of remodeling units that starts in a given time-period) and slightly reduced the remodeling period, while the length of the formation period relatively increased (32). After the first year of treatment, mean OC and PICP levels progressively declined whereas mean ICTP levels remained stable until the final height. In any case, mean bone marker levels remained significantly higher than baseline. Boot et al. (33) showed a peak of OC and PICP at 6 months and a peak of ICTP at 1 year of GH treatment in children with GHD. After 2 years of treatment, according to our results, serum PICP levels significantly declined and serum ICTP levels did not change with respect to baseline values but, in contrast to our data, serum OC levels remained stable (33). Our results suggest that long-term GH treatment is associated with increased bone turnover mainly during the first year of therapy. The stimulation of bone turnover induced by GH treatment could be a main cause of the acquisition of bone mineral density in children with GHD $(33,34)$.

The dynamics of the bone markers could suggest the occurrence of a progressive prevalence of bone resorption with respect to bone formation during GH treatment, and some consideration should be given to this. It has been estimated that as much as $70 \%$ of the OC produced is primarily secreted into the blood and the rest incorporated into the bone matrix (4). Because there is no evidence that this ratio would remain constant when bone growth and bone mineral density are markedly accelerated, a greater fraction of OC may be incorporated into the bone matrix for bone formation and mineralization. PICP reflects the production of type I collagen that occurs during proliferation of osteoblast precursors cells and its synthesis is down-regulated when bone matrix mineralization is attained (27). Thus, the decline in OC and PICP levels that we showed after the first year of treatment could reflect a recovery of bone mineral density, as shown in children with GHD during GH therapy $(33,34)$. However, it must be considered that PICP in serum is secreted not only from bone but also from fibroblasts $(3,4)$. On the other hand, one must be cautious when interpreting serum ICTP levels as a marker of bone resorption, because ICTP may also derive from extraosseus sources of type I collagen that may contribute to increasing its circulating levels (35). At any rate, bone markers provide only a qualitative assessment of bone formation or resorption, and their serum levels cannot be completely translated into rates of bone formation or resorption (36). Thus, it may be unjustified to compare the degree of variation of bone formation markers with bone resorption markers because they are different markers, probably reflecting different aspects of growth. Indeed, a small change in one marker may be more important than a large change in another marker. Measurement of more specific and sensitive biochemical markers of bone turnover, such as serum bone alkaline phosphatase isoenzyme or urinary excretion of collagen cross-links, could provide more 
accurate information on bone turnover during $\mathrm{GH}$ treatment. Finally, during GH treatment bone markers reflect a combination of growth, modeling, and remodeling of bone tissue $(1,2)$.

Circadian and day-to-day variations in bone marker levels may be additional confounding factors in evaluating the dynamics of bone turnover $(1,2)$. Indeed, OC, PICP, and ICTP levels follow a similar circadian rhythm with peak values occurring in early morning and nadirs in the afternoon $(1,30,37)$. Circadian variation in bone markers appears to be unaffected by age and sex (38), as well as by growth and ageing (39). Furthermore, in children with GHD, we previously demonstrated that both nocturnal and diurnal 12-h mean data for OC and PICP were significantly lower than controls, but the pattern of their circadian rhythms was maintained (30). In any case, in the present study, serum samples for the measurement of the bone markers were drawn under standardized conditions in both patients and controls. Although bone markers showed a day-to-day variation, their mean per cent variation did not differ among patients during the study, as well as between patients and controls. These data suggest that in our patients the dynamics of bone markers during the study was probably poorly influenced by circadian and day-today variations.

Compared with healthy children (8-11, 40-42), pubertal development did not influence the pattern of OC, PICP, and ICTP levels in our patients. However, in healthy children no variation in PICP levels was also shown during puberty $(11,14)$. The decline in growth rate during the pubertal stages could explain the lack of increase in bone marker levels during puberty. The shorter duration of pubertal growth in our patients than in normal adolescents ( 5.2 years and 4.8 years in boys and girls respectively) (43) may be an additional factor influencing the dynamics of these bone markers during puberty.

Some studies have shown that, in children with GHD, the absolute values or the changes in OC $(13,15,18)$, PICP $(10,14,16,17)$, or ICTP (18) levels during the first weeks or months of GH treatment predicted growth velocity during the first year of therapy, indicating that bone formation (OC and PICP) or bone resorption (ICTP) was closely related to the effect of GH in stimulating growth rate. In our patients, the lack of prediction of growth rate during long-term treatment or of final height by the changes in bone markers at 6 and 12 months of therapy suggests that other factors influence longitudinal body growth independently of the effect of $\mathrm{GH}$ on bone turnover. Moreover, it must be considered that OC, PICP, and ICTP are not specific markers of longitudinal growth which is primarily a function of the growth plate cartilage activity (2) (42).

In conclusion, our study demonstrates that GH status markedly influences bone turnover in children with GHD. Before treatment, OC, PICP, and ICTP levels were reduced, suggesting that GHD affects bone turnover.
The increment in the bone marker levels during GH therapy indicates that bone turnover is stimulated by the treatment. Furthermore, the changes in OC, PICP, and ICTP levels at 6 and 12 months of treatment do not predict growth rate during long-term GH treatment or final height. At any rate, because many factors may influence final height in children with GHD, further studies are needed to verify the potential value of the biochemical markers of bone turnover for predicting final height in children with GHD.

\section{References}

1 Calvo MS, Eyre DR \& Gundberg CM. Molecular basis and clinical application of biological markers of bone turnover. Endocrine Reviews 199617 333-368.

2 Schonau E \& Rauch F. Markers of bone and collagen metabolism. Problems and perspectives in paediatrics. Hormone Research 1997 48 (Suppl 5) 50-59.

3 Eriksen EF, Brixen K \& Charles P. New markers of bone metabolism: clinical use in metabolic bone disease. European Journal of Endocrinology 1995132 251-263.

4 Risteli L \& Risteli J. Biochemical markers of bone metabolism. Annals of Medicine 199325 385-393.

5 Parfitt AM, Simon LS, Villanueva AR \& Krane SM. Procollagen type I carboxy-terminal extension peptide in serum as a marker of collagen biosynthesis in bone. Correlation with iliac bone formation rates and comparison with total alkaline phosphatase. Journal of Bone and Mineral Research 19872 427-436.

6 Eriksen EF, Charles P, Melsen F, Mosekilde L, Risteli L \& Risteli J. Serum markers of type I collagen formation and degradation in metabolic bone disease: correlation with bone histomorphometry. Journal of Bone and Mineral Research 19938 127-132.

7 Charles P, Mosekilde L, Risteli L, Risteli J \& Eriksen EF. Assessment of bone remodeling using biochemical indicators of type I collagen synthesis and degradation: relation to calcium kinetics. Bone and Mineral 199424 81-94.

8 Johansen JS, Giwercman A, Hartwell D, Nielsen CT, Price PA, Christiansen C et al. Serum bone Gla-protein as a marker of bone growth in children and adolescents: correlation with age, height, serum insulin-like growth factor 1 , and serum testosterone. Journal of Clinical Endocrinology and Metabolism $198867273-$ 278 .

9 Saggese G, Bertelloni S, Baroncelli GI \& Di Nero G. Serum levels of carboxyterminal propeptide of type I procollagen in healthy children from 1st year of life to adulthood and in metabolic bone disease. European Journal of Pediatrics 1992151 764-768.

10 Kubo T, Tanaka H, Inoue M, Kanzaki S \& Seino Y. Serum levels of carboxyterminal propeptide of type I procollagen and pyridinoline crosslinked telopeptide of type I collagen in normal children and children with growth hormone $(\mathrm{GH})$ deficiency during $\mathrm{GH}$ therapy. Bone 199517 397-401.

11 Crofton PM, Wade JC, Taylor MRH \& Holland CV. Serum concentrations of carboxyl-terminal propeptide of type I procollagen, amino-terminal propeptide of type III procollagen, cross-linked carboxyl-terminal telopeptide of type I collagen, and their interrelationships in schoolchildren. Clinical Chemistry 199743 1577-1581.

12 Kikuchi T, Hashimoto N, Kawasaki T, Kataoka S, Takahashi H \& Uchiyama M. Plasma levels of carboxy terminal propeptide of type I procollagen and pyridinoline cross-linked telopeptide of type I collagen in healthy school children. Acta Paediatrica 199887 825-829.

13 Johansen JS, Jensen SB, Riis BJ, Rasmussen L, Zachmann M \& Christiansen C. Serum bone Gla-protein: a potential marker of growth hormone $(\mathrm{GH})$ deficiency and the response to $\mathrm{GH}$ therapy. Journal of Clinical Endocrinology and Metabolism 199071 122126. 
14 Trivedi P, Risteli J, Risteli L, Hindmarsh PC, Brook CGD \& Mowat A. Serum concentrations of the type I and III procollagen propeptides as biochemical markers of growth velocity in healthy infants and children and in children with growth disorders. Pediatric Research 199130 276-280.

15 Kanzaki S, Hosoda K, Moriwake T, Tanaka H, Kubo T, Inoue M et al. Serum propeptide and intact molecular osteocalcin in normal children and children with growth hormone $(\mathrm{GH})$ deficiency: a potential marker of bone growth and response to GH therapy. Journal of Clinical Endocrinology and Metabolism 1992751104 1109.

16 Saggese G, Baroncelli GI, Bertelloni S, Cinquanta L \& Di Nero G. Effects of long-term treatment with growth hormone on bone and mineral metabolism in children with growth hormone deficiency. Journal of Pediatrics 1993122 37-45.

17 Tapanainen P, Knip M, Risteli L, Kemppainen L, Kaar M-L \& Risteli J. Collagen metabolites in the prediction of response to $\mathrm{GH}$ therapy in short children. European Journal of Endocrinology 1997 $137621-625$.

18 Vihervuori E, Turpeinen M, Siimes MA, Koistinen H \& Sorva R. Collagen formation and degradation increase during growth hormone therapy in children. Bone $199720133-138$.

19 Saggese G \& Cesaretti G. Criteria for recognition of the growthinefficient child who may respond to treatment with growth hormone. American Journal of Diseases of Children 1989143 1287-1293.

20 Tanner JM, Whitehouse RH \& Takaishi M. Standards from birth to maturity for height, weight, height velocity, and weight velocity: British children - 1965. Archives of Diseases in Childhood 196641 454-471, 613-634.

21 Greulich WW \& Pyle SI. Radiographic Atlas of Skeletal Development of the Hand and Wrist, edn 2. Stanford, CA: Stanford University Press, 1959.

22 Tanner JM \& Whitehouse RH. Clinical longitudinal standards for height, weight, height velocity, weight velocity and stages of puberty. Archives of Diseases in Childhood 197651 170-179.

23 Ranke MB. Growth hormone therapy in children: when to stop? Hormone Research 199543 122-125.

24 Risteli L \& Risteli J. New markers of collagen synthesis and degradation. In Paediatric Osteology - New Developments in Diagnostics and Therapy, pp 193-202. Ed E Schonau. Amsterdam: Elsevier, 1996.

25 Carey DE, Goldberg B, Ratzan SK, Rubin KR \& Rowe DW. Radioimmunoassay for type I procollagen in growth hormonedeficient children before and during treatment with growth hormone. Pediatric Research 199519 8-11.

26 Delmas PD, Chatelain P, Malaval L \& Bonne G. Serum bone Glaprotein in growth hormone deficient children. Journal of Bone and Mineral Research 19861 333-338.

27 Stein GS, Lian JB \& Owen TA. Relationship of cell growth to the regulation of tissue-specific gene expression during osteoblast differentiation. FASEB Journal 19904 3111-3123.

28 Zamboni G, Antoniazzi F, Radetti G, Musumeci C \& Tatò L. Effect of two different regimens of recombinant human growth hormone therapy on the bone mineral density of patients with growth hormone deficiency. Journal of Pediatrics $1991119483-$ 485.

29 Baroncelli GI, Bertelloni S, Ceccarelli C \& Saggese G. Measurement of volumetric bone mineral density accurately determines degree of lumbar undermineralization in children with growth hormone deficiency. Journal of Clinical Endocrinology and Metabolism 1998 83 3150-3154.

30 Saggese G, Baroncelli GI, Bertelloni S, Cinquanta L \& Di Nero G.
Twenty-four-hour osteocalcin, carboxyterminal propeptide of type I procollagen, and aminoterminal propeptide of type III procollagen rhythms in normal and growth-retarded children. Pediatric Research 199435 409-415.

31 Ohlsson C, Bengtsson B-A, Isaksson OGP, Andreassen TT \& Slootweg MC. Growth hormone and bone. Endocrine Reviews $19981955-79$.

32 Bravenboer N, Holzmann P, De Boer H, Roos JC, Van Der Veen EA $\&$ Lips P. The effect of growth hormone $(\mathrm{GH})$ on histomorphometric indices of bone structure and bone turnover in $\mathrm{GH}$ deficient men. Journal of Clinical Endocrinology and Metabolism 199782 1818-1822.

33 Boot AM, Engels MAMJ, Boerma GJM, Krenning EP \& De Muinck Keizer-Schrama SMPF. Changes in bone mineral density, body composition, and lipid metabolism during growth hormone $(\mathrm{GH})$ treatment in children with $\mathrm{GH}$ deficiency. Journal of Clinical Endocrinology and Metabolism 199782 2423-2428.

34 Saggese G, Baroncelli GI, Bertelloni S \& Barsanti S. The effect of long-term growth hormone $(\mathrm{GH})$ treatment on bone mineral density in children with GH deficiency. Role of GH in the attainment of peak bone mass. Journal of Clinical Endocrinology and Metabolism 199681 3077-3083.

35 Bollerslev J, Moller J, Thomas S, Djoseland O \& Christiansen JS. Dose-dependent effects of recombinant human growth hormone on biochemical markers of bone and collagen metabolism in adult growth hormone deficiency. European Journal of Endocrinology $1996135666-671$.

36 Weaver CM, Peacock M, Martin BR, McCabe GP, Zhao J, Smith DL et al. Ouantification of biochemical markers of bone turnover by kinetic measures of bone formation and resorption in young healthy females. Journal of Bone and Mineral Research 199712 1714-1720.

37 Hassager C, Risteli J, Risteli L, Jensen SB \& Christiansen C. Diurnal variation in serum markers of type I collagen synthesis and degradation in healthy premenopausal women. Journal of Bone and Mineral Research 19927 1307-1311.

38 Nielsen HK, Brixen K \& Mosekilde L. Diurnal rhythm and 24-h integrated concentrations of serum osteocalcin in normals: influence of age, sex, season, and smoking habits. Calcified Tissue International 199047 284-290.

39 Eastell R, Simmons PS, Colwell A, Assiri AMA, Burritt MF, Russell RGG et al. Nyctohemeral changes in bone turnover assessed by serum bone Gla-protein concentration and urinary deoxypyridinoline excretion: effects of growth and ageing. Clinical Science $199283375-382$.

40 Rottevel J, Schoute E \& Delemarre-van de Waal HA. Serum procollagen I carboxyterminal propeptide (PICP) levels through puberty: relation to height velocity and serum hormone levels. Acta Paediatrica 199786 143-147.

41 Sorva R, Anttila R, Siimes MA, Sorva A, Tahtela R \& Turpeinen M. Serum markers of collagen metabolism and serum osteocalcin in relation to pubertal development in 57 boys at 14 years of age. Pediatric Research 199742 528-532.

42 De Ridder CM \& Delemarre-van de Waal HA. Clinical utility of markers of bone turnover in children and adolescents. Current Opinion in Pediatrics 199810 441-448.

43 Marshall WA. Puberty. In Human Growth, pp 141-148. Eds F Falkner \& JM Tanner. London: Bailliere Tindall, 1978.

Received 8 June 1999

Accepted 15 January 2000 